\title{
El Caso Honecker y el Partido Comunista de Chile: una visión desde las páginas de El Siglo (1991-1994)*
}

The Honecker Case and the Commuist Party of Chile: a view from the pages of El Siglo (1991-1994)

Erna Ulloa Castillo*

Cristián Medina Valverde ${ }^{* * *}$

Resumen: El artículo busca establecer cómo el diario El Siglo, órgano del Partido Comunista de Chile (PCCh), abordó el denominado "Caso Honecker". Analiza la manera en que éste medio abordó un caso complejo que enfrentó diplomáticamente a Chile a partir de 1991 con la Alemania de Helmut Kohl y la Rusia de Boris Yeltsin, luego del ingreso de ex líder germano-oriental a su embajada en Moscú en diciembre de 1991. La investigación aborda la visión de un sector político e ideológico cercano, más que a la propia figura de Honecker, a lo que él representó como líder de un sistema que había desaparecido -la RDA- y con el que se tenía una deuda de gratitud Nibelungentreue- por su ayuda durante el exilio. El estudio se complementa con fuentes diplomáticas inéditas del Archivo General Histórico del Ministerio de Relaciones Exteriores de Chile (AGHMINREL), Archivo Patricio Aylwin y entrevistas.

Palabras Claves: El Siglo, Prensa chilena, Caso Honecker, Partido Comunista de Chile

\begin{abstract}
The article seeks to establish how the newspaper El Siglo, organ of the Communist Party of Chile (CCP), addressed the so-called "Honecker Case". It analyzes the way in which this medium dealt with a complex case that diplomatically confronted Chile from 1991 with the Germany of Helmut Kohl and the Rusia of Boris Yeltsin, after the entry of a former East German leader to his embassy in Moscow in dicember 1991. The research addresses the vision of a political and ideological sector close, more than to the very figure of Honecker, to what he represented as leader of a system that had disappeared- the RDA- and with which he owed a debt of gratitude-
\end{abstract}

\footnotetext{
* Proyecto CONICYT / FONDECYT Regular N 1170184, "Historia de las Relaciones Internacionales de Chile: El "Caso Honecker". Tensiones internacionales y conflictos interno en la pos Guerra Fría: Chile 1988-1994

* Chilena. Doctora en Historia, Universidad de Valladolid, Profesora Asistente, Departamento de Historia, Facultad de Comunicación, Historia y Ciencias Sociales, Universidad Católica de la Santísima Concepción. eulloa@ucsc.cl

${ }_{* * *}$ Chileno. Doctor en Historia, Universidad Complutense de Madrid, Profesor Investigador, Instituto de Historia, Facultad de Derecho y Gobierno, Universidad San Sebastián. cristian.medina@uss.cl
} 
Nibelungentreue- for his help during the exile. The study is complemented by unpublished diplomatic sources of the General Historical Archive of the Ministry of Foreing Affairs of Chile (AGHMINREL), Patricio Aylwin Archive and interviews.

Keywords: El Siglo, Chilean Press, Honecker Case, Chilean Communist Party

Recibido: 18 marzo 2019 Aceptado: 4 septiembre 2019

\section{Introducción}

Tras la caída de la República Democrática Alemana (RDA) en 1990 y la posterior reunificación alemana liderada por Helmut Khol, vino para Erich Honecker un periodo complejo marcado por las acusaciones de violaciones a los Derechos Humanos, un incierto estado de salud con informes médicos contradictorios, un refugio de más de siete meses en la embajada chilena en Moscú, para finalmente morir en 1994 en Chile donde aún se conservan sus cenizas.

El presente artículo tiene como marco referencial un episodio que no ha llamado la atención de la historiografía internacionalista tanto chilena como extranjera, en relación a las implicancias intermésticas que tuvo el ingreso de Erich Honecker a la Embajada chilena en Moscú en diciembre de 1991. En lo específico, no existe un trabajo que profundice en el accionar que desarrolló El Siglo frente a este intrincado caso diplomático, como tampoco que estudie la posición que tomó este medio frente a las estrategias que desplegó el gobierno de Patricio Aylwin para resolver el affaire. El tema se complejiza ya que no fueron pocos los chilenos, incluidos algunos integrantes del gabinete presidencial, que encontraron en la Alemania de Honecker refugio y acogida luego del 11 de septiembre de 1973.

En la revisión completa del semanario El Siglo entre 1991 y 1994 encontramos diversas noticias e informaciones vinculadas directamente con Honecker y su círculo más íntimo. Este medio de comunicación nos resultó el más interesante para aproximarnos a la posición del PCCh frente al "Caso Honecker" y conocer las razones de un sector político que vivió su exilio en la RDA y que sintió que tenía con él una deuda de gratitud.

A través de un análisis cualititativo se expone a partir de las diferentes secciones de El Siglo -notas informativas, de opinión y reportajes-, los aspectos temáticos que este medio partidista publicó. De igual forma, hemos abarcado de manera exploratoria lo sostenido por Héctor Borrat en orden a la técnica de exclusión, inclusión y jerarquización de la información en torno a lo que quiso entregar El Siglo a la opinión pública. ${ }^{1}$ En tal sentido, nos hemos planteado como hipótesis que este semanario enarboló una defensa irrestricta a la figura de Honecker y una dura crítica al accionar del gobierno de Aylwin tanto en la conducción la

${ }^{1}$ Héctor Borrat, El periódico, un actor político, Barcelona, Editorial Gustavo Gil, 1989, pp.38-42. 
crisis como también en la solución alcanzada la que estuvo lejos del ideal del PCCh que era lograr el asilo para el ex jerarca.

\section{Consideraciones Previas}

“Ha muerto ayer el camarada Erich Honecker (...) El Siglo vocero del pueblo trabajador chileno, marginado, pero nunca derrotado, rinde homenaje a Honecker y entrega su saludo de pesar a sus familiares y a su pueblo". ${ }^{2}$

El "Caso Honecker" significó para el Gobierno chileno y su diplomacia el despliegue de sus mejores recursos y estrategias para evitar que la situación terminara dañando al país, luego de su retorno a la democracia tras 17 años de dictadura. En este escenario, la prensa chilena -y también alemana- se transformó en un actor más dentro de este conflicto diplomático tripartito que involucró a Chile, Alemania, la Unión de República Socialista Soviética (URSS), posteriormente Rusia. Ejemplo de ello es cómo El Siglo brindó una cobertura amplia a los temas de su interés en este "caso" y los silencios que se detectan ante otros que inundaban el momento histórico-informativo. Entre ellos, por ejemplo, el abandono de Honecker por parte de sus antiguos camaradas rusos, algo que no hizo un sector de la izquierda chilena y El Siglo se encargó de recordarlo constantemente, invocando y detallando la ayuda material que recibieron aquellos chilenos exiliados en la RDA.

Por otra parte, la relación del PCCh con el gobierno de Patricio Aylwin no fue fácil, la colectividad no formó parte de la Concertación de Partidos por la Democracia, coalición política que asumió el poder en Chile en 1990. ${ }^{3}$ Por lo tanto, no se sentía parte del círculo gobernante más aún si consideramos su postura ante las denominadas "leyes de amarre" que había dejado la dictadura. A pesar de ello, actuaron bajo el marco del nuevo sistema político y parlamentario, lo que no fue óbice para mantener una actitud de movilización permanente ("sin movilización no hay democracia") sumado a los conflictos internos en los inicios de 1990 con la marginación y expulsión de militantes históricos. ${ }^{4}$

De modo paralelo, el escenario internacional estaba viviendo quizás su mayor transformación desde la II Guerra Mundial ya que en el último periodo de la Guerra Fría se precipitó la caída del Muro de Berlín, la disolución del Pacto de Varsovia y el colapso de la URSS. Es en este contexto nacional e internacional donde se desarrolla el "Caso Honecker", el último jerarca de un Estado que ya no existía -la RDA-, que buscó asilo y protección entre sus antiguos camaradas de la URRSS, otro Estado que también se disolvió; finalmente viajó a Chile por razones humanitarias cuando éste retornaba a la democracia tras 17 años de

\footnotetext{
2 El Siglo 30 de mayo 1994, p.5.

3 Este conglomerado estuvo formado por el Partido Socialista, la Democracia Cristiana, el Partido por la Democracia y el Partido Radical Social Demócrata desde 1990 hasta el 2010. Remitimos a: Abraham Quezada, “Inserción Internacional de Chile en la Post-Guerra Fría”, Revista Enfoques, Vol. VII, No13, 2010, p. 119-134.

4 Un total de ocho militantes encabezados por Patricio Hales se separaron del Partido puesto que consideraban que la conducción de éste se había alejado de los intereses del pueblo chileno. La Nación, 11. abril 1990, p.12. Asimismo, dentro de los nombres ligados a los que se marginaron se encontraban Fanny Pollarolo, Luis Gustavino, Antonio Leal, entre otros. La Nación, 10 agosto 1990, p.11
} 
dictadura. De alguna manera su situación "mostraba por todos los rincones cómo la historia de Chile estaba fundida con la historia de la política mundial del siglo XX" ${ }^{5}$

Así las cosas, cuando Honecker cae en desgracia y se inicia la etapa de la reunificación alemana, el gobierno de Helmut Kohl emprendió la tarea de hacer justicia por los hechos ocurridos durante su mandato, especialmente aquellos vinculados con la violación de los derechos humanos de los que se responsabilizó al ex-jerarca socialista. Una acusación que para El Siglo era infame y sobretodo un verdadero montaje político liderado por el propio Kohl y un juez "anticomunista", Hans Georg Brautigamm, y que de acuerdo a sus páginas éste incluso le había deseado la muerte a Honecker cuando estuvo en la cárcel en Moabit. 6 Viejos aliados también se sumaron a la incomodidad que provocaba el líder de la ex RDA, entre ellos, Mijail Gorbachov7, quien en todo caso, le había extendido una invitación a Erich Honecker y su esposa para que se trasladaran a Moscú en marzo de 1991 cuando ya pesaba sobre él una orden de detención. ${ }^{8}$

La estancia del matrimonio en Moscú tuvo contratiempos ligados principalmente al estado de salud de Honecker y a las constantes reclamaciones de Alemania a los rusos para que se lo entregaran. Más complejo aún resultó, en ese momento, el proceso de descomposición de la URSS así que Honecker no era una prioridad para el Kremlin, algo de lo que él tenía claridad absoluta. La carta que le remitió al propio Gorbachov da cuenta de ello al sentenciar que él no volvería a Alemania hasta que se levantara su orden de captura, ocasión en que también solicitó apoyo para viajar a Chile, donde vivían su hija Sonja, esposa del chileno Leonardo Yáñez, y sus dos nietos. ${ }^{9}$

La negativa a su petición complicó aún más su situación, no tenía pasaporte ni visa para abandonar Moscú y dirigirse a otro país, estaba ante un callejón sin salida. Es ahí cuando decidió presentarse el 11 de diciembre de 1991, junto a su esposa Margot, en la embajada chilena en Moscú accediendo a una invitación de Irma Cáceres, esposa del embajador Clodomiro Almeyda. ${ }^{10}$ En el interior de la legación diplomática Honecker sufrió un ataque cardíaco que lo llevó a recibir las primeras atenciones médicas y luego la calidad de "huésped" de la embajada. ${ }^{11}$ Con ello se dio inició a un tenso y complejo problema

\footnotetext{
5 Joaquín Fermandois, Mundo y fin de mundo. Chile en la política mundial 1900-2004, Santiago, Ediciones Universidad Católica de Chile, 2005, p.538.

${ }^{6}$ El Siglo, 14 enero 1994, p.12.

7 Véase: Thomas, Kunze, Staatschef a.D. Die letzten Jahre des Erich Honeckers, Berlin, Ch. Links Verlag, 2001; James, McAdams, A., "The Honecker Trial: The East German Past and German Future", The Review of Politics, vol. 58, No 1, 1996, pp.53-80; Uwe Wesel, Der Honecker-Prozess: ein Staat vor Gericht, Frankfurt am Main, Eichborn, 1994; William Taubman, Gorbachov. Vida y época, Barcelona, Debate, 2018, p. 627; Arne Westad, Odd, La Guerra Fría. Una historia mundial, Barcelona, Galaxia Gutenberg, 2018, p. 561 y ss.

8 AGHMINREL, Mensaje secreto N 551, Fondo James Holger, vol. 2, 20 de diciembre de 1991; Jorge Sandrock, El caso Honecker en relación al asilo diplomático y el proceso en la República Federal de Alemania, Tesis para optar al grado de Licenciado en Derecho, Pontificia Universidad Católica de Chile, 1997.

${ }^{9}$ Luis Corvalán, La otra Alemania, RDA. Conversaciones con Margot Honecker, Santiago, Ical, 2000, p.188.

${ }_{10}$ El embajador Almeyda durante esos días no se encontraba en la embajada en Moscú, sino en Chile; regresó a Moscú el 20 de enero de 1992. Véase AGHMINREL, Télex secreto urgente N 560, Gobierno de Chile, Embajada en Federación Rusa, Moscú, 11 de diciembre de 1991.

11 Los trabajos historiográficos sobre el "Caso Honecker” son escasos: Cristián Medina, Gustavo Gajardo, “De apátrida errante a vecino santiaguino". El Caso Honecker desde las fuentes oficiales (1991-1994), Tzintzun,
} 
diplomático entre Chile, Alemania y la URSS, posteriormente Rusia, en un escenario inédito de derecho internacional en el que la prensa fue un actor no sólo informativo sino también ideológico.

El Siglo se transformó en un vocero activo del "Caso Honecker" en virtud no sólo de su propio compromiso ideológico, también para resaltar constantemente lo que significaba Honecker en la memoria del exilio chileno y que, por tanto, había llegado la hora de mostrar reciprocidad política en los difíciles momentos por los que éste atravesaba. Así una columna de opinión de fines de 1991 señalaba: "Como Presidente de la RDA hizo una contribución considerable en el despliegue de la solidaridad de su país y de su pueblo con la lucha democrática de los chilenos con la tiranía de Pinochet. Miles de nuestros compatriotas encontraron en la RDA su segunda patria". ${ }^{12}$

\section{Lejos de Alemania, se piensa en Alemania}

La caída del Muro de Berlín y el inicio del proceso de reunificación alemana llamó la atención de sectores socialistas y comunistas chilenos entorno a las condiciones sociales e ideológicas que se desarrollaban. Al respecto, El Siglo consideró que los principales problemas frente a este tema fueron la persecución política a diversos líderes comunistas, cesantía y escasez de bienes, el desempleo y la pérdida de beneficios sociales que gozaban los ciudadanos de la ex RDA. Como era de esperar también criticó como el capitalismo estaba absorbiendo el modelo que había gobernado por más de treinta años.

Bajo este contexto para fines del primer semestre de 1991 y estando en Moscú viviendo en una dacha que le proporcionó el gobierno ruso, Erick Honecker manifestó su preocupación por los sucesos que ocurrían en Alemania, lo que fue inmediatamente recogido por El Siglo. En un extenso reportaje, publicado en su sección internacional, se valorizaron sus dichos como una declaración de alto valor político y moral en defensa del socialismo, en momentos en que en ese país ocurría verdadera cacería de brujas al más puro estilo de lo que hicieron los nazis contra los comunistas y socialdemócratas: “¿en qué derecho se basa la justicia alemana para juzgar sobre la historia?, ¿de dónde toma el derecho para juzgar 40 años de historia alemana e internacional?. ${ }^{13}$ Las interrogantes plasmaban una crítica directa a los tribunales de la Alemania de Kohl como también al ministro de Justicia,

Revista de Estudios Históricos,México, Nº6, enero-junio, 2017, pp. 260-284; Cristián Medina, Gustavo Gajardo, "Entre protectores y opositores: Labor política frente al Caso Honecker", Revista de Ciencia Política (RCP), Santiago, Pontificia Universidad Católica de Chile, N³, 2016, pp.731-748; Iván Witker, “El Caso Honecker, el interés nacional y la política exterior de Chile: contornos y trasfondo de un problema interméstico", Revista del Centro de Estudios Públicos (CEP), Santiago, N 105, 2007, pp.241-265; Gustavo Gajardo, Chile y el caso Honecker. 1988-1994. Aspectos históricos, diplomáticos y políticos de una crisis internacional, Tesis para optar al grado académico de Licenciado en Historia, Universidad Católica de la Santísima Concepción, Chile, 2014. Sandrock, op.cit; Claudio Orrego, "The status and rights of refugees under International Law: New Issues in light of the Honecker affair", Inter-american Law Review, Miami, 1994, vol. 25, Rev. 351, University of Miami Law School, pp.351-391; Ascanio Cavallo, La historia oculta de la transición. Memoria de una época. 1990-1998, Santiago, Uqbar editores, 2013, pp. 180-197.

12 El Siglo, 1-7 diciembre 1991, p.4.

13 El Siglo, 21-17 julio, 1991, p. 25. 
Klaus Kinkel. Por otro lado, hay que visualizar esta declaración también como una autodefensa frente a las acusaciones que sindicaron a Honecker como el responsable de "lesiones y homicidios ocurridos durante los dieciocho años en que fue Secretario General del Partido Socialista Unificado de la República Democrática Alemana (SED)" ${ }^{14}$

De igual modo, otra temática que jerarquizó en importancia El Siglo en sus publicaciones, fue la idea de establecer que la RDA fue un Estado legal y reconocido por la comunidad internacional, incluso justificó el actuar no sólo de sus líderes sino también de oficiales y soldados que en el decir de Honecker sólo habían cumplido su labor bajo el amparo y reconocimiento de la propia Cámara del Pueblo la que, por cierto, había firmado acuerdos en concordancia con las resoluciones del Tratado de Varsovia. Asimismo, a través de este reportaje, El Siglo resaltó la crítica de Honecker entorno a que el nuevo gobierno de Alemania estaba instrumentalizando los ataques hacia lo que fue su administración como una manera de alcanzar la unidad interna del país, en otras palabras, la venganza del triunfador sobre el vencido: "nada de eso traerá surgimiento económico ni término de la cesantía, ni tampoco conduce a un futuro mejor de la Juventud", sentenció. ${ }^{15}$

Además de estas reflexiones, El Siglo también plasmó en sus páginas la preocupación de su esposa, Margot, sobre el futuro familiar inmediato debido a la fragilidad política en la que se encontraban en Moscú. De allí la urgencia de definir un tercer país donde ser recibidos y vivir tranquilamente sin el temor de que su esposo fuera extraditado. Sobre Honecker pesaba una orden de detención la que para El Siglo no era más que un medio para restar valor y criminalizar la política que implementó en la RDA. Bajo este contexto la esposa de Honecker realizó un viaje a Chile en octubre de 1991, que recibió amplia cobertura en El Siglo siendo el único medio de prensa escrita chileno que no sólo la entrevistó, sino que también la acercó emocionalmente con sus simpatizantes. ${ }^{16}$ En tal sentido se buscó potenciar la idea que ya habían hecho sentir sectores de la izquierda chilena, sobre la "reunificación familiar" como una estrategia para que Honecker pudiera salir de Moscú en dirección a Chile, idea que fue un argumento reiterativo en los primeros meses del affaire. ${ }^{17}$

La llegada y la estadía de Margot Honecker en Chile fue breve y silenciosa, habló muy poco con la prensa, salvo El Siglo, como hemos indicado y a Televisión Nacional de Chile (TVN). Bajo el titular "Conversación con Margot Honecker en Isla Negra", El Siglo realizó una entrevista bastante descriptiva y con tintes de crónica: "Margot Honecker es esbelta, de regular estatura tiene hermosos ojos azules y una sonrisa que ilumina su rostro. Amable y sencilla, se hace querer de inmediato" ${ }^{18}$ A medida que avanza la entrevista, lo hace también la descripción de la casa de Neruda y la emoción que en ella le produjo estar

\footnotetext{
14 Medina y Gajardo, “De apátrida errante a vecino santiaguino”, op.cit, p. 265.

15 El Siglo, 21-17 julio, 1991, p. 26.

16 El Siglo 20-26 octubre 1991, pp.12-13.

17 Entrevista a Ricardo Núñez, 5 de junio de 2018. Político socialista chileno, presidente de la colectividad 19911992, vicepresidente de la Internacional Socialista, y Embajador de Chile en México. Entrevista a Enrique Correa, 6 de julio de 2018. Ex Ministro Secretario General de Gobierno de Chile 1990-1994.

18 El Siglo 20-26 octubre 1991, pp.12
} 
allí: "Estoy muy feliz de haber encontrado, otra vez, a Neruda a quien queremos y admiramos, Neruda es Chile y Chile nos habla con palabras de Neruda" ${ }^{19}$

El resto de sus declaraciones giraron sobre dos ejes: la situación judicial de su marido y su anhelo de poder vivir en Chile junto a su hija y nietos. Así tenemos que la segunda parte de este reportaje se basó en una entrevista muy al estilo de perfil humano, destacando lo relevante del sentido familiar y el hecho que su única hija viviera en Chile con sus dos hijos, Roberto de 16 años y Vivian 3 años respectivamente. ${ }^{20}$ Para Margot, Chile era un país que los acogía como si fuera su propia tierra y el hecho de estar en Moscú la había alejado de sus nietos, especialmente de la menor. Pero no sólo apelaría al lazo sanguíneo, sino también al de esposa, dedicando sentidas palabras para su marido a quien calificaba como un hombre bondadoso más allá de su círculo familiar: "Es muy emotivo y espontáneo. Nunca se sintió bien en el mundo del protocolo. Los años de enfrentamiento con el fascismo fortalecieron su espíritu y disciplina". ${ }^{21}$

La entrevista trasunta una apelación a la emotividad, a lo que significa vivir en otro país, enlazando ello con lo que les tocó vivir a muchos chilenos en el exilio. ${ }^{22}$ En este sentido, El Siglo potenció la urgente necesidad de los Honecker de estar en un país libre de tensiones, lo que de paso no sólo sería beneficioso para el círculo familiar, sino también para el estado de salud de Erich ${ }^{23}$. Hay que recordar que antes que él viajara a Moscú, había sufrido un ataque al miocardio 24 , con lo cual en los meses posteriores el término "frágil estado de salud" se unirá al de "reunificación familiar", algo que El Siglo tuvo presente en la mayor parte de sus publicaciones, tanto durante su estancia en la embajada chilena en Moscú como hasta su llegada a Chile.

Ahora bien, al realizar un análisis de la entrevista y la fecha de esta, consideramos que El Siglo buscó instalar incipientemente tanto entre sus simpatizantes como en la opinión pública chilena la deuda de gratitud que se tenía con los Honecker por toda la ayuda que entregaron a un importante número de compatriotas que vivieron el exilio en la RDA

${ }_{19}$ El Siglo 20-26 octubre 1991, p. 12. Frase que Margot Honecker escribiría en el libro de visitas de la casa de Neruda.

20 Véase el relato autobiográfico de Roberto Yáñez, Thomas Grimm, Ich war der letzte Bürger der DDR. Mein Leben als Enkel der Honeckers, Berlín, Insel Verlag GmbH, 2018.

${ }^{21}$ El Siglo 20-26 octubre 1991, p.12

22 Muchos chilenos vivieron parte de su exilio en la desaparecida RDA, entre las cuales figuraron connotadas personalidades del Partido Socialista de Chile. Remitimos a: APAA, Carta del Presidente Patricio Aylwin al Canciller alemán, Helmut Kohl, Archivo Institucional Universidad Alberto Hurtado, CL CLUAH 1-72-2-6, 16 XII-1991; Rolando Álvarez, Rolando; Julio Pinto y Verónica Valdivia, Verónica, Su revolución contra nuestra revolución: Izquierdas y derechas en el Chile de Pinochet 1973 - 1981. Santiago: LOM, 2006 p 105; Patricia Politzer, Patricia, Altamirano. Santiago, Debate, 2013; Clodomiro Almeyda, Reencuentro con mi vida, Santiago, Ornitorrinco, 1987, pp. 281 - 282. Sobre exiliados chilenos remitimos a: Luis Corvalán, El derrumbe del poder soviético. Santiago, Los Andes, 1993, p. 87; Odette Magnet, “Socialistas chilenos: Como vivieron en la RDA". APSI, No 417, del 23 de marzo al 5 de abril de 1992, pp. 13; Daniel Palma, "La vida de los exiliados políticos chilenos. Luces y sombras de un 18 de septiembre", Revista Contribuciones, No 127, Universidad de Santiago de Chile, 2001, pp.155-179; Faride Zerán, “O el asilo contra la opresión, 23 historias para recordar". Análisis, N 405, 9 al 22 de diciembre de 1991, pp. $21-23$.

23 El Siglo 20-26 octubre 1991, p.13.

24 Corvalán, La otra Alemania, RDA. op.cit, p.95. Este ataque que sufrió Honecker fue durante su estancia en el hospital militar soviético en Beelitz, entre Berlín y Leipzig, en abril de 1990. 
(chilenische patrioten), así que ahora se tenía la oportunidad de retribuir ello. Asimismo, días antes de esta entrevista a Margot líderes del socialismo chileno, como Camilo Escalona, solicitaron al gobierno de Patricio Aylwin que le otorgara asilo político a Honecker en Chile. Incluso las acciones de apoyo no se detuvieron allí, ya que pocas semanas después del viaje de Margot a Chile, El Siglo informó de una carta del PCCh solicitando recibir al ex jerarca alemán: "Como han hecho otros sectores políticos y sociales del país el PC, ha insistido por carta, suscrita por Volodia Teitelboim y dirigida al canciller Silva Cimma, de que el gobierno autorice el ingreso a Chile del ex Presidente del Consejo de Estado de la RDA, Erick Honecker". 25

Quizás lo que no estuvo en los cálculos ni del El Siglo ni del PCCh es que semanas después de la entrevista, el 11 de diciembre de 1991, el matrimonio Honecker llegaría a la embajada chilena en Moscú y permanecería en ella por casi siete meses. Como ellos mismos dijeron, no estaban solicitando asilo y no abandonarían por voluntad propia el lugar, por lo que el gobierno de Patricio Aylwin frente a esto, les otorgó la calidad de "huésped". ${ }^{26} \mathrm{Al}$ respecto, el mismo Honecker declaró:

He tomado conocimiento a través de los medios de comunicación de una declaración del gobierno de Chile según la cual no se me brindaría asilo político. Al respecto deseo aclarar que hasta la fecha nunca he solicitado asilo político a Chile, sino que he pedido únicamente que se me permita ingresar a ese país para permanecer con mi familia. ${ }^{27}$

\section{Llegada a la embajada}

El ingreso de los Honecker a la embajada chilena en Moscú tomó por sorpresa a La Moneda, aunque surgieron dudas sobre si el embajador, Clodomiro Almeyda, sabía lo que iba a suceder. En lo concreto, la declaración oficial de la Embajada chilena fue que ellos habían ingresado libremente y que serían "huéspedes" en la sede diplomática. ${ }^{28}$ Lo que no indica este documento es la existencia de una orden de expulsión de Honecker de territorio ruso emitida el 10 de diciembre de 1991, por lo tanto, éste debía abandonar el país en un plazo de tres días lo que precipitó su ingreso a la legación al no tener ya otras opciones. ${ }^{29}$

A nivel informativo la situación descrita provocó un revuelo internacional, se multiplicaron las informaciones que daban cuenta de este hecho, sin embargo, El Siglo demoró en publicar algo al respecto ${ }^{30}$, recién en su edición del 22 al 28 de diciembre de 1991,

\footnotetext{
25 El Siglo 1-7 diciembre 1991, p. 4.

${ }_{26}$ Medina, "El huésped (in) esperado. Erich Honecker en la embajada de Chile en Moscú”, op.cit., pp. 49-5. Medina y Gajardo, “De apátrida errante a vecino santiaguino", op.cit., pp. 260-284.

27 AGHNINREL, Télex Ordinario Urgente N564, Gobierno de Chile, Embajada en Federación Rusa, Moscú, 12 de diciembre 1991.

28 AGHNINREL, Télex Secreto Urgente N 560, Gobierno de Chile, Embajada en Federación Rusa, Moscú, 11 de diciembre 1991.

${ }_{29}$ AGHMINREL, Protocolo sobre Notificación de resolución de expulsión del territorio de la Federación Rusa, Fondo James Holger, vol. 2, 12 de diciembre de 1991.

30 El Siglo se publicaba semanalmente, pero para 1993, veremos un cambio publicándose diariamente.
} 
con Honecker ya instalado en la embajada, publicó un breve artículo en que sutilmente deslizó que éste se encontraba en la delegación chilena: “(...) fue acogido como huésped por el embajador Clodomiro Almeyda en Moscú". ${ }^{31}$ Esta primera publicación se enfocó principalmente en resaltar la gestión de la República Popular Democrática de Corea para recibir a Erich Honecker: "Corea del Norte le abrió las puertas a Honecker". El Siglo, reconoció en este país la afinidad ideológica y la generosidad de los norcoreanos para acoger al otrora ex jerarca de la RDA, destacando cómo Corea era también un país dividido siendo un sector absorbido por las ideas del capitalismo estadounidense: “(...) la RDA ha sido absorbida por el capitalismo salvaje, luego de un complejo proceso que impactó al mundo". 32

El Siglo también aprovechó la ocasión para plantear una crítica directa al gobierno de Aylwin al quebrar la tradición chilena y no concederle inmediatamente asilo a Honecker, una crítica curiosa puesto que éste, como hemos indicado, en ningún momento apeló a ello como revelan las fuentes. ${ }^{33}$ Aun así, estas voces no se acallaron y El Siglo hizo eco de ello recogiendo, por ejemplo, las declaraciones del entonces secretario general del PCCh, Volodia Teitelboim: " acogerlo no sólo corresponde a un sentimiento entrañablemente, sino a un deber, a un imperativo de conciencia y a un principio de reciprocidad". 34

Pero El Siglo no sólo buscó establecer en la opinión pública la emotividad o empatía por la situación de Honecker, también buscó resaltar que Chile como país libre, soberano y en transición a la democracia no podía ni debía dejarse amedrentar por las presiones de la Alemania de Helmut Kohl. Esto por cuanto apenas Honecker pisó la embajada chilena en Moscú, los alemanes llamaron a entregarlo a su gobierno de manera inmediata y sumaria. Incluso Dieter Kastrup, subsecretario de Relaciones Exteriores de Alemania, indicó al propio embajador chileno en Bonn, Carlos Huneeus, que ellos no aceptarían la salida de Honecker a un tercer país ya que éste debía comparecer ante los tribunales alemanes. ${ }^{35}$

Paralelo a la discusión diplomática, las expresiones de solidaridad por parte del PCCh no sólo se desplegaron en El Siglo, sino también en diversas manifestaciones que organizó ante la embajada alemana en Santiago, hasta donde llegaron simpatizantes y miembros del PCCh para leer públicamente una carta que el partido había enviado al presidente Patricio Aylwin solicitándole expresamente que se le permitiera a Honecker poder vivir en Chile:

Nos sentimos comprometidos profundamente con la RDA, con su gobierno y con la digna conducta de Erick Honecker, activo luchador antifascista de toda su vida, prisionero por 10 años en las cárceles de Hitler. Apelamos también a razones de

\footnotetext{
31 El Siglo 22-28 diciembre 1991, p.16.

32 El Siglo 22-28 diciembre 1991, p.16

33 Algunos autores han insistido en que Erich Honecker solicitó asilo a Chile, algo que no aparece en la revisión de las fuentes. Véase Ricardo Martín de la Guardia, La caída del Muro de Berlín, El final de la Guerra Fría y el auge de un nuevo mundo, Madrid, La Esfera de los Libros, 2019, p. 109; Witker, op.cit., 241-265.

${ }^{34}$ El Siglo, 22-28 diciembre 1991, p.16.

${ }^{35}$ AGHMINREL, Télex Reservado Urgente No 072, Gobierno de Chile, Embajada en Alemania, Bonn, 19 de Febrero de 1992, p. 21.
} 
hondo contenido humanitario, que son parte del acervo de generaciones de chilenos que han aportado al engrandecimiento de la patria. ${ }^{36}$

Una actitud muy contraria a la que estaban teniendo, según el PCCh, algunos miembros de la alianza de Gobierno que en su momento recibieron ayuda de la RDA y que ahora no estaban socorriendo a quien en el pasado los había acogido, así por lo menos lo publicó El Siglo a través de un artículo de opinión: “(...) callan y no hacen nada por conseguir la única salida jurídica, política y éticamente consecuente: el asilo en Chile a Erich Honecker". ${ }^{37}$ Al transcurrir las semanas y no existir claridad respecto a la situación de Honecker, El Siglo profundizó su crítica sobre el accionar del gobierno de Patricio Aylwin calificando a la Cancillería como débil ante las presiones alemanas e inclusos rusas. Así lo dejó de manifiesto en una declaración pública en su edición del 18 de febrero de 1992:

Rechazamos la actitud pusilánime de la Cancillería chilena para enfrentar estas presiones que lesionan nuestra soberanía e independencia. El Partido Comunista reitera una vez más, la exigencia de asilo para Erich Honecker. Las explicaciones para no hacerlo más allá de la acrobacia verbal del Ministro Silva Cimma, más parecen debilidad o cálculo mezquino. Más inconsecuente aún que provengan de un gobierno que no escatima esfuerzos para que verdaderos criminales, como Pinochet, gocen de inmunidad y poder, en nuestro país. ${ }^{38}$

Ante ello el PCCh a través de El Siglo consideró que el gobierno chileno estaba asumiendo una actitud timorata y contradictoria en su actuar, algo que dentro del propio gobierno y de su coalición ya se había dejado sentir. Un claro ejemplo de ello fueron las diferencias al interior del Partido por la Democracia (PPD) donde algunos de sus miembros, como el diputado Felipe Valenzuela, apelaron a la tradición de asilo de Chile, mientras que Jorge Schaulsohn, presidente de la colectividad, indicó que no se podía otorgar asilo a Honecker ya que contravenía los principios de la ONU por la violación a los derechos humanos: "El asilo político no corresponde en el caso del señor Honecker, quien está donde debe estar". ${ }^{39}$ De igual manera la figura del embajador Almeyda provocaba conflicto, incluso para algunos debía ser removido de su cargo, mientras que para otros como el Partido Socialista (PS) de ocurrir esto se desataría una crisis política interna. Ante ello El Siglo fue enfático en reconocer el trabajo que estaba realizando el PS en orden a mantener un equilibrio: “El desafío simultáneo de mantener su relación con la Concertación, defender

\footnotetext{
36 APAA, Carta del Partido Comunista de Chile sobre otorgación de asilo político a Erick Honecker, Archivo Institucional Universidad Alberto Hurtado, CL CLUAH1-69-2-1, 16 de diciembre 1991.

37 El Siglo 6-12 junio, 1992, p.6.

38 El Siglo 23-29 febrero 1992, p.5. Para ese momento -y tras el plebiscito de 1990 y el triunfo de la Concertación de Partidos por la Democracia- el Gral. Augusto Pinochet se mantuvo como Comandante en Jefe del Ejército hasta marzo de 1998 para luego asumir como senador vitalicio.

${ }_{39}$ Cámara de Diputados, Sesión 25․ Situación planteada por la permanencia del señor Erick Honecker en la embajada chilena en Moscú, Valparaíso, 5 agosto 1992; Cámara de Diputados, Sesión $34^{\circ}$. Procedencia de calidad de huésped otorgada a Erick Honecker, Valparaíso, 17 diciembre 1991.
} 
a Honecker e impedir la salida de Almeyda, no les ha sido fácil y han debido enfrentar presiones que no disminuirán". 40

En definitiva, para El Siglo la situación entorno a Honecker dejaba importantes interrogantes, no sólo por las discusiones que se estaban produciendo al interior del país, sino que también, por lo que estaba sucediendo a nivel internacional en términos de la imputación judicial a Honecker la que se basaba en una acusación- Anklageschrift- por parte de la Fiscalía de Berlín por la responsabilidad de la muerte de 49 personas que trataron de cruzar el muro de Berlín -Schießbefehl- durante la década del setenta. ${ }^{41}$ Un hecho que El Siglo no dejó de comentar y que incluso calificó como curioso, ya que el caso lo estaba llevando la misma fiscalía que no había condenado a ningún nazi ni grupos de nazis tras la II Guerra Mundial: “La fiscalía de Berlín se caracterizó por después de la guerra no condenar a ningún criminal nazi. Incluso quedó libre uno de los jueces de la justicia hitleriana que condenó a muerte a 250 antifascistas". 42

Frente a este tema, consideramos que El Siglo llevó a cabo un proceso de inclusión informativa, puesto que para potenciar la idea de injustificada acusación en contra de Honecher y que era viable que viajara a un tercer país, el semanario recogió una publicación del diario Berliner Morgen Past (de Berlín occidental) para indicar que Richard Schroeder, un activo político que defendía la idea de cambio en la RDA, reconocía que no era un problema que Honecker terminara sus días en Chile junto a su familia, puesto que el resto "lo harían los historiadores" en términos de la valoración a través del tiempo.

\section{¿Expulsión o abandono voluntario de la embajada?}

Con el correr de las semanas, el no tener claridad de que Honecker llegaría a residir en Chile y tras siete meses como "huésped" en la embajada chilena en Moscú, su salida resultaba ser para El Siglo un hecho inminente, ya que para este semanario cada vez tomaban más fuerza aquellos sectores que estaban dispuestos a entregarlo a la justicia alemana en cualquier momento, así por lo menos quedó registrado en una columna de opinión bajo el título Comedia de Equivocaciones: "En efecto, todo indica que las tratativas oficiales se orientan en este sentido y el enrarecido ambiente criollo pone la atención sobre tan nefasta posibilidad". ${ }^{3}$

En lo concreto, se llevaron a cabo numerosas y complejas negociaciones diplomáticas, se esgrimieron diversas estrategias y argumentos jurídicos para que éste finalmente llegara a comparecer ante los tribunales alemanes. El proceso le significó al gobierno chileno desplegar sus mejores herramientas en el ámbito diplomático, en este sentido y ante los resquemores que provocaba el embajador Almeyda, el presidente Aylwin designó un enviado especial para llevar a cabo las negociaciones ante rusos y alemanes, el

\footnotetext{
40 El Siglo 22-28 marzo 1992, p.15.

41 Entrevista a Roberto Cifuentes, 20 de marzo de 2018. Ex embajador, asesor especial del presidente Patricio Aylwin en asuntos internacionales 1990-1994, ex embajador de Chile en Alemania 1994-1998. http://www.robertocifuentesallel.cl/

42 El Siglo 20-26 octubre 1991, p.14.

43 El Siglo 4-10 abril 1992, p.6.
} 
embajador James Holger Blair, hasta ese momento Embajador Alterno de Chile ante las Naciones Unidas. ${ }^{44}$ Le acompañaron en esta tarea Roberto Cifuentes, asesor presidencial para asuntos internacionales y el diplomático Jorge O’ Ryan. ${ }^{45}$. Al respecto, consideramos que sobre este asunto El Siglo llevó adelante un tema de exclusión informativa, por cuanto en sus publicaciones hubo un total y absoluto silencio en torno a la designación de Holger y su equipo, sólo se remitió a informar brevemente de lo preocupante que era para la política exterior del país, la ausencia de Almeyda en sus labores diplomáticas en Moscú y que el gobierno se prestara a recibir a personajes que sólo buscaban revanchismo político, una clara alusión a la visita que hizo a La Moneda el presidente del partido Liberal de Alemania, Otto lambsdorff, lo que El Siglo no dejo pasar: “Los mismos que poco antes habían recibido al estadista Erich Honecker con los honores correspondientes a su cargo, hoy se aprestan al festín anticomunista. Los herederos de Hitler con insaciables". ${ }^{46}$

Ahora bien, la misión de Holger y su equipo era buscar una solución jurídica entre las partes involucradas, pero la posición de Chile era compleja producto de varias razones: Alemania se opuso a que Honecker viajara a un tercer país; el gobierno de Aylwin no debía mostrar que estaba cediendo ante las presiones rusas y alemanas y, en tercer lugar, había que encontrar una solución que satisficiera a todos. ${ }^{47}$ En este contexto, además, para Chile era relevante el respeto a las garantías procesales, es decir, que existiera el derecho a defensa en el caso que Honecker fuera expulsado: "Lo que Chile pretende, no es convertirse en defensor o vocero de Sr. Honecker, sino que se respete el derecho internacional, fundamento de la concesión de la calidad de huésped temporal (...) Chile solamente solicita que se apliquen en la Federación de Rusia los mecanismos jurídicos que son pertinentes" ${ }^{48}$

Para fines de marzo de 1992 la idea de expulsarlo de la legación chilena tomó fuerza e incluso Honecker estuvo dispuesto a hacer abandono de ella, pero bajo la condición de que las autoridades rusas le permitieran presentar un recurso para revisar la orden de expulsión. Chile entendió que dicha petición era justa, pero no así los rusos. Por lo demás, el propio Boris Yeltsin ya se había comprometido con Helmut Kohl para enviar al "huésped" a Bonn una vez que dejará su refugio diplomático. Esto llevó incluso al propio Canciller chileno, Silva Cimma, a reclamar ante las autoridades rusas y alemanas por lo que consideraba un no querer ceder ante la búsqueda de soluciones, además, existió para Santiago una responsabilidad de la Federación Rusa como sucesora de la URSS. ${ }^{49}$ Frente a esto, una visión muy contraria tuvo El Siglo que lo plasmó en una nota de opinión bastante crítica, indicando que al Gobierno le faltaba carácter y por eso se dejaba presionar: "La Cancillería muestra en forma flagrante su debilidad. Horquillada por las presiones del

44 AGHMINREL, Cable secreto N44, Fondo James Holger, Vol.1, marzo 1992; AGHMINREL, Cable Secreto Nº6, Fondo James Holger, Vol.1, marzo 1992, Vol.1, ARREE-AJH.

45 El abogado Roberto Cifuentes fue embajador de Chile en Alemania en el periodo 1994.1998. Por su parte Jorge O“Ryan también fue embajador de Chile en Alemania durante los años 2010-2014. Actualmente es el Director de Pro-Chile https://www.prochile.gob.cl/

46 El Siglo 11-17 julio 1992, p.6.

47 AGHMINREL, Mensaje oficial, Cable Secreto $N^{\circ} 9$, del Ministro de relaciones Exteriores de Chile al embajador James Holger, Fondo James Holger, Vol.1, 8 abril de 1992.

48 AGHMINREL, Télex Secreto N99, Fondo James Holger, Vol., 8 abril 1992.

${ }^{49}$ AGHMINREL, Télex Secreto N¹1, Fondo James Holger, Vol.1, 8 abril 1992. 
conocido y antiguo revanchismo alemán y el autoritarismo remanente en la ex Unión Soviética, el gobierno de Aylwin vacila, se contradice, se retrotrae y engaña a la opinión pública internacional". ${ }^{50}$

El engaño al cual se refería El Siglo, se relacionó con que hubo una ausencia constante por parte del gobierno de Aylwin en brindarle a Honecker la documentación necesaria para que pudiera salir de Moscú y no comparecer así ante los tribunales germanos: “(...) el gobierno de Aylwin espera una decisión de las autoridades rusas o alemanas y ni siquiera está solicitando salvoconducto, pasaporte o cualquier válido para que el huésped de la embajada chilena en Moscú pueda viajar". 51

En este sentido y de acuerdo a la documentación diplomática, el gobierno de Aylwin no entregaría a Honecker sin un procedimiento judicial en Rusia, basando su argumentación en el artículo 13 del Pacto de Derechos Civiles y Políticos (1966): “Chile no pide nada que no sea estrictamente ajustado a las normas internacionales, pero no está dispuesto a aceptar tampoco nada que constituya una violación a dichas normas". 52 El gobierno nunca se opuso a que Honecker se presentara ante los tribunales alemanes, no desconocía el Estado de Derecho en ese país, pero sí discrepaba en torno a los mecanismos para llegar a ello.53 Por su parte, la postura alemana fue de rechazo del art.13 del Pacto de Derechos Civiles y Políticos e insistió hasta el agotamiento, y por todas las vías posibles, en la entrega sumaria e inmediata del "huésped".

Finalmente, tras una serie de encuentros diplomáticos, incluida la reunión entre Aylwin y Kohl en el marco de la Cumbre de Río de Janeiro (junio, 1992) hecho que El Siglo no cubrió en sus páginas, y las conversaciones entre el embajador Holger y el Subsecretario Dieter Kastrup, terminaron sellando el destino de Honecker que no era otro que presentarse ante los tribunales alemanes. Al respecto, eso sí, el gobierno chileno propuso que los alemanes hicieran una solicitud de restitución de Honecker ante la Federación Rusa siendo estos quienes determinarían si el "huésped" de la embajada chilena tenía derecho a defenderse. La medida fue estratégica para Chile por cuanto mostró que no se estaba intercediendo de forma especial por Honecker y dejaba en manos rusas determinar si éste tendría derecho a defensa.

Los rusos determinaron que Honecker tendría un plazo 24 horas para presentar su defensa aunque en un inicio se habló de 48 horas: "La autoridad rusa había accedido a conceder solamente 24 horas para que el huésped hiciera uso del derecho mencionado debido a que -según ellos- el señor Honecker "había tenido más de siete meses para defenderse". 54 Como es de imaginar un plazo menor dificultó elaborar una defensa adecuada, así que no quedó más que iniciar los preparativos de la salida, la que se concretó

50 El Siglo 6-14 marzo 1992, p.6.

51 El Siglo 6-14 marzo 1992, p.6.

52 AGHMINREL, Antecedentes y fundamentos para entrevista con Viceministro Kolokolov, Fondo James Holger, Vol.4, 1 abril de 1992; AGHMINREL, Télex Secreto N¹1 y N¹2, Fondo James Holger, Vol.1, 8 abril de 1992.

53 AGHMINREL, Minuta de trabajo del Embajador James Holger para las conversaciones que sostendrá con autoridades alemanas en Bonn, RFA, entre 27-29 de mayo de 1992, Fondo James Holger, Vol.4, 25 mayo 1992.

54 AGHMINREL, Reunión sostenida entre el embajador James Holger con el matrimonio Honecker", Fondo James Holger, Vol.4, 27 de julio 1992. 
a fines de julio, día en que los rusos emitieron una declaración breve y escueta a la prensa: “Hoy en julio 29 de 1992, el Sr. Honecker dejó territorio ruso en Moscú y ha sido trasladado a Berlín”. 55

El impacto informativo no se hizo esperar y El Siglo que si bien durante el último tiempo de las negociaciones entre los meses mayo - junio mantuvo un discreto silencio, no hizo lo mismo una vez que Honecker abandonó la embajada chilena en Moscú. Así, a inicios de agosto el semanario no se reservó comentario alguno frente a lo que calificó como una: "flagrante derrota para Chile como país soberano e independiente". ${ }^{56}$ Pero no sólo eso, sino que publicó en la primera edición de agosto de 1992, una portada con un irónico titular haciendo giño a uno de los versos del himno patrio, un lema que obliga una promesa y cumplimiento: “O el asilo contra la opresión”, acompañado, por cierto, de la que es quizás la más icónica fotografía de este "caso", como es la de Honecker saliendo de la embajada con el puño izquierdo en alto, con Margot a su espalda, acompañado por los diplomáticos James Holger, y en segundo plano, Jorge O’Ryan y José Miguel Cruz. Ahora bien, este no sería el único juego de palabras en un titular, ya que luego, en modo de reportaje al interior de este semanario, se aludió nuevamente al emblema heráldico nacional: "Por la razón o la fuerza" para resaltar por un lado, las características que tuvo la salida de Honecker de la embajada chilena la que fue sentenciada como "condenable", y por otro lado, el juicio al que se le iba a someter en Berlín..$^{57}$ Una situación que, según el abogado del ex jerarca alemán, Friedrich Woiff, violaba los principios del derecho internacional. En este sentido, El Siglo resaltó sus dichos a través de un reportaje que abordó el impacto del juicio, incluso El Siglo inició dicho texto periodístico con las propias palabras Woiff: "He leído la acusación contra Honecker. Se trata de un escrito político y no de otra cosa. Estoy más convencido que nunca de la inocencia de mi defendido". 58

El amplio reportaje buscó también asentar una mirada panorámica de las diversas aristas vinculadas a este caso. Una de éstas fue informar a la opinión pública la situación social en la que se encontraba Alemania, la cual luego de dos años desde la caída del Muro los resultados de la reunificación al parecer no eran los esperados, y las críticas a Kohl en el ámbito de la seguridad social se estaban haciendo sentir. Al menos así lo declaró el Partido Social Demócrata puesto que en una encuesta que aplicaron los primeros días de agosto de 1992, arrojó que el 73\% de los alemanes de la ex RDA extrañaban las condiciones sociales de dicho régimen. 59

Bajo este contexto, El Siglo no sólo se refirió a dicha encuesta, también jerarquizó la información, haciendo eco de las diversas posturas de ciudadanos alemanes como también de las propias autoridades germanas referidas al trato que recibió Honecker. Puntualmente, El Siglo resaltó este último aspecto recordando y comparando cómo a fines de los años ochenta Honecker invitado por el propio Helmut Kohl viajó a Bonn: “Honecker fue recibido

55 AGHMINREL, Reunión sostenida por el embajador Holger con el embajador Fokin, Fondo James Holger, Vol.4, 28 de julio de 1992.

56 El Siglo 1-7 agosto 1992, p.3.

57 El Siglo 1-7 agosto 1992, p.2.

58 El Siglo 1-7 agosto 1992, p.2.

${ }^{59}$ El Siglo 1-7 agosto 1992, pp.2-3. 
en Bonn por las autoridades y los políticos más representativos de la RFA con alfombra roja y todas las galas del protocolo. Hoy esas mismas autoridades esperan a Honecker para llevarlo a prisión". ${ }^{60} \mathrm{Al}$ respecto, el historiador A. James Mc Adams, señaló que en Bonn se tuvo cuidado de definir la presencia de Honecker en esa ocasión como una visita de trabajo y no como visita de Estado. ${ }^{6}$

Otra arista informativa que utilizó El Siglo fue reproducir en sus páginas la opinión de un sector de la prensa alemana frente al retorno de Honecker a suelo germano, por ejemplo, Neues Deutschland, que fue el periódico del propio partido político de Honecker (SED) y luego del Partido del Socialismo Democrático, criticó la actitud de Helmut Kohl y recordó cómo éste sólo un par de años antes, tuvo muestras de amabilidad y cordialidad con Erich Honecker, en clara alusión al encuentro entre ambos líderes que indicábamos anteriormente. Otro medio de prensa al que aludió El Siglo fue el diario Express de Colonia, afirmando que Honecker había abandonado la embajada chilena en Moscú ya que había sido amenazado con el uso de la violencia por parte de las autoridades chilenas. Para respaldar esto indicó que el embajador James Holger sostuvo con el ex líder alemán una "fatigosa conversación" tras lo cual habría ingresado a la embajada chilena un equipo de la seguridad rusa que le indicó a Honecker que lo sacarían a la fuerza si no accedía a abandonar el lugar, ante lo cual no tuvo más opción que someterse a lo que se le estaban indicando, hechos que El Siglo respaldaba: "La versión del Express coincide con la del abogado Vogel a quien Honecker le dijo que no había viajado a Berlín voluntariamente". ${ }^{62}$. Ahora bien, según las fuentes diplomáticas esta afirmación resulta ser infundada: "Ninguno de los funcionarios rusos subió al cuarto de Honecker, quien fue acompañado sólo por el Encargado de Negocios, Cruz, el T.S, O’ Ryan y el suscrito para los efectos de cambiarse de ropa, arreglar sus maletas y preparar su salida. (...) lo que sí es importante señalar es que no hubo apremio físico ni uso de la fuerza contra el Sr. Honecker". 63

En la misma sintonía de los otros medios de prensa, el Frankfurter Rundschau consideró inexplicable el trato a un hombre que había sido jefe de Gobierno por trece años de un estado soberano y no sólo eso, sino de un estado reconocido tanto por la ONU y por la RFA. Por su parte el diario berlinés, Tagesspiegel hizo eco de los rumores acerca de cómo fueron efectivas las presiones del gobierno alemán, tanto a rusos como a chilenos, para que Honecker abandonara la embajada. Señaló incluso que éste habría solicitado un recurso legal para aclarar si procedía la extradición, también se especuló acerca de una carta que le entregó a James Holger cuando abandonó su refugio diplomático y que pidió se entregara las autoridades rusas. Al respecto y en lo concreto debemos indicar que al analizar tanto las publicaciones de El Siglo, la prensa alemana y las fuentes diplomáticas, se demuestra que

\footnotetext{
60 El Siglo 1-7 agosto 1992, p.3. Para complementar el hecho histórico remitimos a: David Childs, Germany in the Twentieth Century, London, Routledge, 2015, pp.236-236

61 James McAdams, Germany Divided. From the wall to reunification, Princeton New Jersey, Princeton University Press, 1993, p. 173.

62 El Siglo 1-7 agosto 1992, p.3

63 AGHMINREL, Télex Secreto S/N, de Embajador James Holger al Ministro de relaciones Exteriores de Chile, Fondo James Holger, Vol.1, 31 de agosto de 1992.
} 
las negociaciones para lograr la salida del "huésped" de la embajada fueron de sumo complejas. James Holger señaló que:

(...) pocos días antes de la partida del Sr. Honecker esas conversaciones habían llegado a un total impasse, logramos superar la situación a través de una fórmula de última hora que, sin comprometer nuestros principios, dio a la parte rusa la necesaria "salvada de cara" para aceptarla. De no haber asumido nosotras esa actitud, el Sr. Honecker estaría todavía en nuestra embajada con el riesgo de que su permanencia se hubiese consolidado, transformándose con ello al huésped en un segundo Cardenal Mindzensky con los efectos que ello hubiese causado. ${ }^{64}$

Resulta evidente que el espacio entregado por El Siglo para reproducir la información que venía de un sector de la prensa alemana con la que tenía afinidad ideológica, tuvo por objetivo fortalecer la idea de que el gobierno de Helmut Kohl no sólo quería castigar públicamente a Erich Honecker, sino también plasmar el descontento de un sector de la opinión pública, que provenía de la ex RDA, que no estaba recibiendo los beneficios de un nuevo sistema social y económico que había pregonado convertir a la ex RDA en "campos florecientes". .5

El recuerdo de la visita de Honecker a Bonn en 1987 fue un recurso utilizado en gran parte de las publicaciones de El Siglo durante el mes de agosto, que es donde más información se generó entorno a este caso. En este sentido, el semanario chileno destacó de manera especial una aguda y crítica declaración del director de la revista alemana Der Spiegel que aludió al enfrentamiento entre acusadores y acusado: “Me gustaría ver en las paredes del tribunal en un gran formato, las fotografías en que aparece Honecker con todos los grandes de la RFA, para los cuales era un interlocutor muy respetado". ${ }^{66}$ También el recurso desplegado, hizo que El Siglo comentara un reportaje que el Canal 1 de la televisión alemana transmitió sobre el encuentro en septiembre de 1987 entre los líderes de las dos Alemania. Ahora bien, este tipo de acciones y el posible impacto en un sector de la opinión pública, nos llevan a pensar que El Siglo consideró que esto podría reforzar la idea de que el trato que estaba recibiendo Honecker era injusto.

A nivel interno del país, El Siglo criticó al Partido Demócrata Cristiano (PDC) por estar de acuerdo con la derecha chilena en la entrega de Honecker a la RFA. Pero no sólo eso, el semanario participó en una concurrida conferencia de prensa en la que la precandidata presidencial por el MIDA67, Gladys Marín, criticó abiertamente a las autoridades chilenas: "El gobierno del presidente Aylwin deberá asumir la responsabilidad histórica de haber roto la tradición jurídica y diplomática chilena -sólo quebrada en los

\footnotetext{
64 AGHMINREL, Télex secreto S/N de Embajador Holger al Ministro de Relaciones Exteriores de Chile, Fondo James Holger, Vol.1, 31 agosto de 1992.

65 Martín de la Guardia, op.cit., pp. 135 y ss.

66 El Siglo 8-14 agosto 1992, p.3.

${ }^{67}$ El Movimiento de Izquierda Allendista, MIDA; fue una coalición política formada por el Partido Comunista, Izquierda Cristiana, Mapu e Izquierda Revolucionaria, que nació en 1991 para enfrentar las elecciones municipales de 1992 y la presidencial y parlamentaria de 1993. Para mayor detalle remitimos a: Patrick Guillaudat, y Pierre, Mouterde, Los movimientos sociales en Chile, 1973-1993, Santiago, LOM, 1998, p.212.
} 
últimos 50 años por Pinochet-, sobre, el principio de asilo político estampado incluso en nuestro himno nacional". 68

Ahora bien, las críticas de El Siglo no sólo se dirigieron al gobierno de Patricio Aylwin sino también responsabilizó a la coalición gobernante de no haber aportado al debate en favor de Honecker y a la independencia del país frente a las presiones ejercidas. En este sentido, el semanario criticó directamente a la Concertación, al considerar que ésta se amparó en declaraciones de la derecha, como la que hizo el diputado de Renovación Nacional Gustavo Alessandri: "Creo que el caso Honecker es una vergüenza... creo que estábamos amparando a una persona que no merece más que el repudio de todos" ${ }^{69} \mathrm{La}$ crítica de El Siglo a la Concertación apuntó a que algunos de sus miembros y reconocidos políticos se mantuvieron al margen de la idea de que Honecker llegara al país y que no habían sido solidarios con quien les ayudó cuando fueron perseguidos por el régimen militar. Uno de los más enfáticos en esta línea argumentativa fue el diputado socialista Mario Palestro, para quien el tema Honecker era netamente un asunto humanitario ya que nadie apoyó ni solidarizó con la odisea que vivió el matrimonio Honecker. En este mismo contexto de crítica, quien fuera durante el Gobierno de la Unidad Popular el agregado cultural y de prensa en la embajada chilena en la RDA entre 1971-1972, Ivan Planells, hizo un llamado de atención a sus camaradas: "a esos dirigentes les recuerdo un pensamiento de Aristóteles cuando dijo que el olvido es señal de menosprecio y por lo tanto, causa enojo"..$^{70}$

El sentir que se le estaba dando la espalda a Honecker es quizás uno de los ejes temáticos centrales en términos de jerarquización informativa que El Siglo plasmó en sus páginas, así lo podemos evidenciar en unos de los pocos editoriales sobre este caso: “... es uno de los episodios más oscuros en la historia diplomática chilena (...) el precedente para la diplomacia chilena es extremadamente grave" ${ }^{71} \mathrm{Si}$ analizamos esta calificación, podemos establecer dos argumentos. En primer lugar, El Siglo consideró una traición al histórico principio de asilo político, que sólo había sido suspendido durante el régimen de Pinochet y en segundo lugar, la deslealtad que esto significaba para con un gobernante que había sido solidario con el pueblo chileno:

Para quienes creemos en los principios, en el socialismo, en la dignidad, es un deber y una gran tarea levantar la más grande solidaridad con Erich Honecker. Exigir su libertad inmediata y el cese de esta campaña anticomunista. En este sentido, El Siglo, asume el desafío y bregará porque la injusticia comedita y la humillación a la tradición chilena, sean reparadas. ${ }^{72}$

Si bien frente al caso Honecker no encontramos entre 1991 y 1994 un alto número de portadas en sus ediciones, luego de la que hizo alusión al himno nacional, sí luego publicó una que también buscó llamar la atención de la opinión pública, esta vez bajo el titular,

68 El Siglo 1-7 agosto 1992, p.2.

${ }^{69}$ El Siglo 1-7 agosto 1992, p.2.

70 El Siglo 22-26 agosto 1992, p.10.

71 El Siglo 1-7 agosto 1992, p.11.

72 El Siglo 1-7 agosto 1992, p.11. 
"Ridículo Mundial", con la bajada, "por unos marcos más, Chile rompió una digna tradición".$^{73}$ Un titular bajo el cual El Siglo buscó graficar el costo que tuvo la decisión del gobierno de Aylwin para la imagen internacional del país, en términos que la salida del ex jerarca fue una "expulsión" y no una salida voluntaria como lo indicó el propio embajador James Holger en una misiva al Canciller Silva Cimma:

(...) salió voluntariamente de la embajada. Lo hizo en la medida que accedió al último llamamiento del suscrito en presencia del Ministro de RR.EE y personal de seguridad ruso (un total de 6 personas). Estos últimos nada hicieron y el único que habló fue el diplomático ruso. (...) Quienes sostienen que Honecker no salió voluntariamente tendrían razón en cuanto la posición del huésped fue permanente rechazo a abandonar la embajada. ${ }^{74}$

Esta declaración no cayó nada de bien al interior del PCCh y El Siglo criticó abiertamente la actitud de James Holger por su rigidez y vehemencia para que el matrimonio alemán rápidamente hiciera sus maletas y abandonara la embajada, como quedó de manifiesto en el artículo de opinión "La imagen de Chile quedó en ridículo", en que declara, por cierto sin citar fuente alguna, lo abrupto de esta actitud: "(...) la rudeza con que Holger, negó a Honecker una hora de plazo para arreglar sus cosas diciéndole: No, usted debe abandonar el suelo de la embajada en este minuto". ${ }^{75}$

El Siglo consideró que se habían violado los derechos humanos de Honecker y calificó el hecho no como abandono sino como "expulsión" de la embajada. Para sostener este punto, el semanario recogió en sus páginas la opinión de diversas organizaciones en el ámbito del derecho internacional e incluso entrevistó a la abogada, diplomática y reconocida especialista chilena en temas internacionales, como es María Teresa Infante. ${ }^{76}$ Si bien rehusó referirse puntualmente a la situación de Honecker, entregó su perspectiva jurídica sobre el asilo diplomático y las condiciones bajo las cuales un Estado puede otorgarlo.

Por su parte, la Comisión Chilena de Derechos Humanos emitió el 5 de agosto de 1992, días después de la salida del "huésped" de la embajada, una declaración pública responsabilizando al Ejecutivo por la falta de firmeza que llevó a entregar a Honecker de una manera "inadecuada". El Siglo también consultó la opinión de la Corporación de Promoción y Defensa de los Derechos del Pueblo (CODEPU), quienes fueron categóricos al respecto. En este sentido, El Siglo entrevistó al abogado de dicha Corporación, Hiram Villagra, para quien la palabra "agradecimiento" se aplicaba para quien prestó ayuda post exilio 1973: “En CODEPU, miramos con algún grado de agradecimiento la figura de

\footnotetext{
${ }^{73}$ El Siglo 8-14 agosto 1992.

74 AGHMINREL, Télex Secreto S/N de Embajador James Holger al Ministro de relaciones Exteriores de Chile, Fondo James Holger, Vol.1, 31 de agosto de 1992.

75 El Siglo 8-14 agosto 1992, p.2.

76 Formó parte como coagente del equipo de jurídico de la defensa de Chile ante la Corte Internacional de Justicia de La Haya frente a la acusación marítima de Bolivia. Para 1992, se desempeñaba como Directora del Instituto de Estudios Internacionales de la Universidad de Chile.
} 
Honecker sin que eso signifique un juicio aprobatorio de su régimen ni de la existencia del muro". ${ }^{77}$

En paralelo a estas informaciones, El Siglo continuó difundiendo ampliamente las críticas de Gladys Marín, pero en esta ocasión más que al Gobierno de modo general, centró su malestar en el ministro Enrique Silva Cimma, cuestionando lo que éste había planteado en términos de que Honecker contaría con las garantías necesarias para un debido proceso. Bajo este contexto, El Siglo publicó una nota informativa, "las falsedades de la cancillería", en la cual recogió las críticas directas de Marín a las declaraciones públicas que hizo el Ministro sobre lo que había sucedido con Honecker: "Afirmamos que la declaración del Ministerio de Relaciones Exteriores contiene una cantidad inmensa de falsedades (...) ¿por qué no se ha entregado a la opinión pública la verdad de lo que ha ocurrido con la salida de Honecker de la embajada chilena?".78

Ahora bien, el análisis de las fuentes disponibles revela que la actitud del Canciller Silva Cimma fue bastante particular, tanto por su hermetismo, como por su tensa relación con el embajador Almeyda y su permanente resistencia a presentarse ante el Congreso para referirse al "Caso Honecker". ${ }^{79}$ Cuando lo hizo, en agosto de 1992, El Siglo, estuvo en la sesión parlamentaria y publicó un reportaje que se inició con una categórica frase: "fueron por la verdad y recibieron golpes y patadas". ${ }^{80}$ De esta manera se refirió El Siglo a la expulsión de dirigentes de izquierda que se encontraban presentes en la sala de la cámara. Tras el término de la exposición del Canciller este solicitó dos minutos de sesión secreta para entregar antecedentes de la salida de Honecker de la embajada chilena en Moscú, lo que provocó la protesta desde la tribuna, por lo que el entonces Presidente de la Cámara, José Antonio Viera Gallo, solicitó el desalojo, pero no sin antes la propia Gladys Marín desde la tribuna exclamara: "digan la verdad de cara al pueblo". 81

Bajo todo este ambiente de convulsión entre parlamentarios y diversos sectores políticos, se votaron dos proyectos: uno desde la propia Concertación que planteó que con la salida de Honecker se daba por cerrado el caso para Chile y se reafirmaba la política exterior del país (la votación fue 44 a favor y 30 votos en contra) y un segundo proyecto vinculado a la oposición que planteó que la Cámara de Diputado debía expresar su molestia por el accionar del gobierno proponiendo el arbitrio para impedir que nuevos casos como este volvieran a ocurrir. El proyecto fue rechazado por 49 votos contra 34.

Para El Siglo a partir de este nuevo escenario, se generaron los espacios informativos en sus páginas para que las palabras de Erich Honecker fueran conocidas. Un claro ejemplo

\footnotetext{
77 El Siglo 8-14 agosto 1992, p.4.

78 El Siglo 8-14 agosto 1992, p.5.

79 Sobre las dilaciones del Canciller chileno ante el Congreso Nacional de Chile, remitimos a: Diario de Sesiones del Senado, República de Chile, Sesión 42, Ordinaria, martes 10 de marzo de 1992, p. 18; Diario de Sesiones del Senado, República de Chile Sesión 02, Ordinaria, miércoles 02 de junio de 1992, pp. 6-7; Diario de Sesiones del Senado, República de Chile Sesión 06, Ordinaria, martes 30 de junio de 1992, p. 42; Diario de Sesiones del Senado, República de Chile Sesión 15, Ordinaria, jueves 06 de agosto de 1992, pp. 6- 8; Diario de Sesiones del Senado, República de Chile Sesión 21, Ordinaria, martes 01 de septiembre de 1992, pp. 13- 14.

${ }^{80}$ El Siglo 8-14 agosto 1992, p.2. Mireya Baltra dirigente ícono de la izquierda, quien sufriría la fractura en su brazo derecho al momento del desalojo.

81 El Siglo 8-14 agosto 1992, p.2.
} 
de esto fue la declaración que éste escribió en la cárcel en Moabit, donde fue llevado tras salir de Moscú a Alemania. Dicho texto no sólo fue enviado a los medios de prensa, sino también llegó a los diversos comités de solidaridad con Honecker que se organizaron tanto en Chile como en otros países: "Lamento mucho que políticos de la República Federal Alemana que durante mi mandato como Presidente del Consejo Estatal de la RDA mantenían conmigo una relación basada en mutuo respeto y con los cuales yo estaba siempre dispuesto a entrevistarme cuando ellos me lo pedían, ahora promueven una caza de brujas, sin precedente contra mí". 82

Las diversas pericias informativas de El Siglo, variaron de acuerdo al desarrollo del "Caso Honecker" y en este sentido, publicar las cartas del exjerarca sobre su condición fue sin lugar a dudas una estrategia comunicacional para respaldar a Honecker en momentos en que éste debía enfrentar a los tribunales alemanes.

\section{Los informes médicos}

Hemos indicado que uno de los puntos relevantes del affaire Honecker fue su real estado de salud. Este aspecto fue gravitante para El Siglo por la nebulosa que lo rodeó durante meses, pero también porque fue un argumento central para esgrimir las razones humanitarias. Inicialmente se informó que padecía cáncer terminal al hígado para luego indicar que padecía una enfermedad menor ${ }^{83}$.

Desde que Honecker ingresó la embajada chilena en Moscú la incertidumbre y preocupación sobre su salud fue un asunto constante en el que incluso hubo informes médicos contradictorios como los febrero de 1992, viajes a un centro médico en Moscú, negociaciones diplomáticas tripartitas para garantizar la seguridad del "huésped" durante su traslado a una clínica por las calles de Moscú e incluso especulaciones de todo tipo, finalmente todo quedó resuelto con los exámenes médicos realizados cuando éste retornó a Berlín para ser enjuiciado. ${ }^{84}$

Bajo este escenario y con Honecker detenido en la cárcel de Moabit como el prisionero 2955-92, durante el mes de agosto de 1992, se le realizaron nuevos exámenes médicos que arrojaron que se encontraba en la fase final de un cáncer hepático, quedándole poco tiempo de vida. Ante este hecho, El Siglo publicó el parte médico que se filtró a la prensa. Rainer Rex, director del servicio de medicina interna del hospital de Moabit, indicó

82 El Siglo 16-21 agosto 1992, p.5.

83 Yañez, y Grimm, op.cit.

84 AGHMINREL, Télex Secreto Urgente n ${ }^{\circ}$ 68, "Informe médico Sr. Honecker”, Gobierno de Chile, Embajada en Federación Rusa, Moscú, 12 de febrero de 1992; AGHMINREL, Télex Secreto Urgente n 37, Gobierno de Chile, Embajada en Federación Rusa, Moscú, 12 de febrero de 1992; AGHMINREL, Télex Reservado Urgente n 72, “E. Honecker", Gobierno de Chile, Embajada en Alemania, Bonn, 19 de febrero de 1992; AGHMINREL, Oficio Reservado No 004, “Comprobante de contabilidad n²29”, Embajada en Federación Rusa, Moscú, 29 de abril de 1992; AGHMINREL, Télex Secreto Urgente n 127, Gobierno de Chile, Embajada en Federación Rusa, Moscú, 3 de 1992. 
que según los resultados de la tomografía realizada, existía "un tumor de cinco centímetros en proceso de desarrollo en el lóbulo derecho del hígado". 85

Esta situación trascendió lo netamente médico transformándose en un asunto político ya que dejó en evidencia que el resultado de los exámenes que se le habían realizado en Moscú en febrero de 1992 habían sido alterados: “El diagnóstico berlinés dejaba al descubierto el engaño cometido por el equipo médico que examinó a Honecker en Moscú dictaminando que no padecía cáncer y que sus condiciones de salud eran buenas". 86 Tal impacto causó esta nueva información médica, que El Siglo en sus páginas centrales, a fines de agosto de ese año, publicó un reportaje titulado "Dictamen falso hunde a Honecker en la prisión" asegurando que de haberse sabido que tenía cáncer su destino habría sido probablemente otro. ${ }^{87}$

Para El Siglo como para el PCCH la contradicción en los partes médicos y el silencio de los rusos significó una verdadera traición a Honecker pero, sobre todo, les preocupó la situación en la que se encontraba éste, de ahí que el semanario planteó si era humano someter a proceso a una persona que iba a morir. ${ }^{88}$ Como respuesta a esta interrogante publicó en extenso diversas opiniones e informes que respaldaban el tema humanitario e incluso declaraciones de autoridades alemanas que planteaban desconocer absolutamente la enfermedad que lo aquejaba. En palabras del vocero de gobierno alemán, Norbert Schaeffner: "Bonn no fue informado en su oportunidad sobre el cáncer". ${ }^{89}$ Este tipo de afirmaciones calaron profundamente en los sectores que apoyaban a Honecker, ya que hizo evidente la deslealtad con el moribundo líder socialista. Como una forma de apoyo, El Siglo publicó cartas y mensajes que llegaban a su redacción y que exigían su libertad inmediata.

A tal nivel llegaron las expresiones de solidaridad que El Siglo se comprometió a dos cosas: seguir publicando párrafos de las cartas recibidas y, en segundo lugar, a realizar todos los esfuerzos para hacer llegar aquellas misivas al propio Honecker en Moabit para "así demostrarle que el pueblo chileno no opina ni actúa igual que su actual Gobierno" 90 . Incluso para el mismo día de su cumpleaños las manifestaciones de apoyo a través de cartas no se detuvieron: “(...) ha recibido, una montaña de cartas, aparte de algunos paquetes".$^{91}$

Para contrarrestar lo que el PCCh consideró como falta de iniciativa de La Moneda en términos de solidaridad, se conformó una agrupación bajo el nombre: "Comando por la Libertad de Honecker", la que tuvo una intensa agenda de actividades que fue desde la realización de actos públicos, encuentros, reuniones e incluso llegaron a entregarle al embajador alemán en Chile, Wiegand Pabsch, una carta solicitando la liberación inmediata de Honecker. Dicha agrupación no sólo estuvo compuesta por miembros de esa tienda política, sino también por algunos miembros de la Izquierda Cristiana (IC), del PS y del PPD. Incluso la agrupación organizó un encuentro con Margot Honecker cuando ella estuvo

\footnotetext{
85 El Siglo 22-26 agosto 1992, p.8.

86 El Siglo 22-26 agosto 1992, p.8.

87 El Siglo 22-26 agosto 1992, pp.8-9.

88 El Siglo 12-18 septiembre 1992, p.4.

89 El Siglo 22-26 agosto 1992, p.9.

90 El Siglo 22-26 agosto 1992, p.9.

91 El Siglo 12-18 septiembre 1992, p.4.
} 
en Chile en octubre de 1992, publicando El Siglo: "La solidaridad le da fuerzas para seguir luchando por el derecho que es pisoteado en la Alemania de hoy. No sólo se viola sus derechos sino los de todos los compañeros procesados" 92

Finalmente, el anhelo de los simpatizantes chilenos de Honecker se cumplió tras su liberación el 13 de enero de 1993, siendo exonerado de toda responsabilidad penal por razones humanitarias debido a su cáncer terminal. El estado alemán le otorgó permiso para viajar a Chile, donde arribó el 14 de enero cerca de las 14 hrs.. ${ }^{93}$ La portada de El Siglo tituló, "Honecker en Chile", recogiendo en sus páginas las primeras impresiones del ex líder de la RDA: “Agradezco la solidaridad de Chile y su pueblo. Todo ha sido difícil. En Berlín quedaron algunos compañeros prisioneros, hay que seguir luchando, hay que seguir luchando". ${ }^{94}$

\section{Conclusiones}

El "caso Honecker" se transformó en un hecho que le significó al gobierno de Patricio Aylwin realizar sus mejores gestiones tanto a nivel diplomático como personal, para que este no terminara afectando el camino hacia el reencuentro democrático y su imagen-país. No ocurrió lo mismo con el PCCh quien vio en el gobierno una actitud poco colaborativa y distante hacia la figura de Honecker y lo que éste representaba.

El papel que desempeñó El Siglo como órgano mediático de la colectividad, fue más allá de lo informativo, constituyéndose en el canal donde se expresaron las más variadas críticas al gobierno, a la Cancillería y al propio Patricio Aylwin al considerar que finalmente se había cedido a las presiones alemanas para que Honecker enfrentara un juicio y la cárcel en Berlín. Ante ello, consideramos que la mayor decepción para este semanario fue el silencio de aquellos que estuvieron exiliados en la RDA durante la dictadura militar y que no consideraron la "vuelta de mano" de quien les había brindado refugio y protección en tiempos de persecución y exilio.

El balance de El Siglo evidencia que desde un inicio no estuvieron de acuerdo en el manejo político y comunicacional que realizó La Moneda frente al "Caso Honecker", sobre todo ante la negativa de otorgarle asilo político en Chile - a pesar de que el propio Honecker en más de una ocasión expresó que nunca lo solicitó- y mantenerlo como "huésped" en Moscú, fue una categoría con la cual el Partido Comunista nunca estuvo de acuerdo.

El argumento de apelar a la reunificación familiar fue una tesis frecuente en las páginas de El Siglo que se vio potenciada y fundamentada con la idea de razón humanitaria una vez que los exámenes médicos demostraron la existencia de un cáncer terminal. El Siglo, por lo tanto, insistirá hasta el agotamiento que no sólo se estaba frente a un líder que había gobernado un Estado reconocido por la comunidad internacional, sino que también se estaba frente a un hombre moribundo que había sido traicionado por sus antiguos camaradas.

\footnotetext{
92 El Siglo 17-23 octubre 1992, p.19.

93 Medina y Gajardo, "De apátrida errante a vecino de Santiago", op.cit. p. 279.

94 El Siglo 16-22 enero 1993, p, 3.
} 
El "Caso Honecker" y su relación con Chile, adquiere una mayor comprensión si se toma en cuenta el interés y la participación activa del PCCh y el rol que en ello desempeñó El Siglo, como un medio de prensa activo e ideológico frente uno de los hechos políticosdiplomáticos más paradigmáticos en la historia internacional reciente de nuestro país.

\section{Referencias bibliográficas}

\section{Fuentes impresas}

Almeyda Clodomiro, Reencuentro con mi vida, Santiago, Ornitorrinco, 1987

Borrat Héctor, El periódico, un actor político, Barcelona, Editorial Gustavo Gil, 1989.

Cavallo Ascanio, La historia oculta de la transición. Memoria de una época. 1990-1998, Santiago, Uqbar editores, 2013.

Corvalán Luis, La otra Alemania, RDA. Conversaciones con Margot Honecker, Santiago, Ical, 2000, p.188. El derrumbe del poder soviético. Santiago, Los Andes, 1993.

Childs David, Germany in the Twentieth Century, London, Routledge, 2015.

Fermandois Joaquín, Mundo y fin de mundo. Chile en la política mundial 1900-2004, Santiago, Ediciones Universidad Católica de Chile, 2005.

Gajardo Gustavo, Chile y el caso Honecker. 1988-1994. Aspectos históricos, diplomáticos y políticos de una crisis internacional, Tesis para optar al grado académico de Licenciado en Historia, Universidad Católica de la Santísima Concepción, Chile, 2014.

Guillaudat Patrick,Mouterde Pierre, Los movimientos sociales en Chile, 1973-1993, Santiago, LOM, 1998. Kunze Thomas, Staatschef a.D. Die letzten Jahre des Erich Honeckers, Berlin, Ch. Links Verlag, 2001.

Martín de la Guardia Ricardo, La caída del Muro de Berlín, El final de la Guerra Fría y el auge de un nuevo mundo, Madrid, La Esfera de los Libros, 2019.

McAdams James, Germany Divided. From the wall to reunification, Princeton New Jersey, Princeton University Press, 1993.

McAdams, A., "The Honecker Trial: The East German Past and German Future", The Review of Politics, vol. 58, No 1, 1996, pp.53-80.

Medina Cristián (et. al.), "El huésped (in) esperado. Erich Honecker en la Embajada de Chile en Moscú", Encuentros. Europa - Iberoamérica en un mundo globalizado, Hungría, Centro Iberoamericano, Universidad de Pécs, Fakultás Kiadó, 2018, pp. 49-59.

Medina Cristián, Gajardo Gustavo, "De apátrida errante a vecino santiaguino". El Caso Honecker desde las fuentes oficiales (1991-1994), Tzintzun, Revista de Estudios Históricos,México, № 65, enerojunio, 2017, pp. 260-284.

Medina Cristián, Gajardo Gustavo, "Entre protectores y opositores: Labor política frente al Caso Honecker", Revista de Ciencia Política (RCP), Santiago, Pontificia Universidad Católica de Chile, $\mathrm{N}^{\circ} 3$, 2016, pp.731-748.

Odette Magnet, "Socialistas chilenos: Como vivieron en la RDA". APSI, No 417, del 23 de marzo al 5 de abril de 1992, pp. 13.

Orrego Claudio, "The status and rights of refugees under International Law: New Issues in light of the Honecker affair", Inter-american Law Review, Miami, 1994, vol. 25, Rev. 351, University of Miami Law School, pp.351-391.

Palma Daniel, "La vida de los exiliados políticos chilenos. Luces y sombras de un 18 de septiembre", Revista Contribuciones, No 127, Universidad de Santiago de Chile, 2001, pp.155-179.

Politzer Patricia, Altamirano. Santiago, Debate, 2013. 
Quezada Abraham, "Inserción Internacional de Chile en la Post-Guerra Fría", Revista Enfoques, Vol. VII, No13, 2010, p. 119-134.

Sandrock Jorge, El caso Honecker en relación al asilo diplomático y el proceso en la República Federal de Alemania, Tesis para optar al grado de Licenciado en Derecho, Pontificia Universidad Católica de Chile, 1997.

Taubman William, Gorbachov. Vida y época, Barcelona, Debate, 2018.

Wesel Uwe, Der Honecker-Prozess: ein Staat vor Gericht, Frankfurt am Main, Eichborn, 1994.

Westad Arnet, La Guerra Fría. Una historia mundial, Barcelona, Galaxia Gutenberg, 2018.

Witker Iván, "El Caso Honecker, el interés nacional y la política exterior de Chile: contornos y trasfondo de un problema interméstico", Revista del Centro de Estudios Públicos (CEP), Santiago, N 105, 2007, pp.241-265.

Yáñez Roberto y Grimm Thomas, Ich war der letzte Bürger der DDR. Mein Leben als Enkel der Honeckers, Berlín, Insel Verlag GmbH, 2018.

Faride Zerán, "O el asilo contra la opresión, 23 historias para recordar". Análisis, No 405, 9 al 22 de diciembre de 1991, pp. $21-23$.

\section{Semanario El Siglo}

El Siglo 21-17 julio 1991.

El Siglo 20-26 octubre 1991.

El Siglo 1-7 diciembre 1991.

El Siglo 22-28 diciembre 1991.

El Siglo 23-29 febrero 1992.

El Siglo 6-14 marzo 1992.

El Siglo 22-28 marzo 1992.

El Siglo 4-10 abril 1992.

El Siglo 6-12 junio, 1992.

El Siglo 11-17 julio 1992.

El Siglo 1-7 agosto 1992.

El Siglo 8-14 agosto 1992.

El Siglo 16-21 agosto 1992.

El Siglo 22-26 agosto 1992.

El Siglo 12-18 septiembre 1992.

El Siglo 17-23 octubre 1992.

El Siglo 16-22 enero 1993

El Siglo 14 enero 1994.

El Siglo 30 mayo 1994.

\section{Documentos inéditos}

Archivo General Histórico Ministerio de relaciones Exteriores de Chile:

Fondo James Holger Vol.1 1991

Fondo James Holger Vol.2 1991

Fondo James Holger Vol.1 1992

Fondo James Holger Vol.2 1992

Fondo James Holger Vol.4 1992

\section{Fondo Embajadas:}


Télex Ordinario Urgente N564, Gobierno de Chile, Embajada en Federación Rusa, Moscú, 12 de diciembre 1991.

Télex Secreto Urgente N 560, Gobierno de Chile, Embajada en Federación Rusa, Moscú, 11 de diciembre 1991.

Télex Secreto Urgente $\mathrm{n}^{\circ}$ 68, "Informe médico Sr. Honecker", Gobierno de Chile, Embajada en Federación Rusa, Moscú, 12 de febrero de 1992;

Télex Secreto Urgente no 37, Gobierno de Chile, Embajada en Federación Rusa, Moscú, 12 de febrero de 1992.

Télex Reservado Urgente no 72, “E. Honecker”, Gobierno de Chile, Embajada en Alemania, Bonn, 19 de febrero de 1992.

Oficio Reservado No 004, “Comprobante de contabilidad n²29", Embajada en Federación Rusa, Moscú, 29 de abril de 1992.

Télex Secreto Urgente n 127, Gobierno de Chile, Embajada en Federación Rusa, Moscú, 3 de 1992.

Télex Reservado Urgente No 072, Gobierno de Chile, Embajada en Alemania, Bonn, 19 de Febrero de 1992.

Sesiones Cámara de Diputados:

Sesión $25^{\circ}$. Situación planteada por la permanencia del señor Erick Honecker en la embajada chilena en Moscú, Valparaíso, 5 agosto 1992.

Sesión $34^{\circ}$. Procedencia de calidad de huésped otorgada a Erick Honecker, Valparaíso,17 diciembre 1991.

\section{Sesiones Cámara de Senado:}

Sesión 42, Ordinaria, martes 10 de marzo de 1992, p. 18; Diario de Sesiones del Senado, República de Chile.

Sesión 02, Ordinaria, miércoles 02 de junio de 1992, pp. 6-7; Diario de Sesiones del Senado, República de Chile.

Sesión 06, Ordinaria, martes 30 de junio de 1992, p. 42; Diario de Sesiones del Senado, República de Chile.

Sesión 15, Ordinaria, jueves 06 de agosto de 1992, pp. 6- 8; Diario de Sesiones del Senado, República de Chile.

Sesión 21, Ordinaria, martes 01 de septiembre de 1992, pp. 13- 14; Diario de Sesiones del Senado, República de Chile.

\section{Prensa}

La Época, 25 de marzo1992

La Nación, 11. abril 1990.

La Nación, 10 agosto 1990.

El Mercurio, 25 de marzo1992.

El Mercurio, 28de marzo1992.

\section{Entrevistas Personales}

Entrevista a Roberto Cifuentes, 20 de marzo de 2018.

Entrevista a Ricardo Núñez, 5 de junio de 2018.

Entrevista a Enrique Correa, 6 de julio de 2018. 